Fisheries Oceanography

Volume 16 Issue 6 Page 506-514, November 2007

http://dx.doi.org/ 10.1111/j.1365-2419.2007.00442.x

(c) 2007 Blackwell Publishing, Inc.
Archimer, archive institutionnelle de l'Ifremer http://www.ifremer.fr/docelec/

The definitive version is available at www.blackwell-synergy.com

\title{
The influence of environment and spawning distribution on the survival of anchovy (Engraulis encrasicolus) larvae in the Bay of Biscay (NE Atlantic) investigated by biophysical simulations
}

\author{
Gwenhael Allain $^{1}$ Pierre Petitgas ${ }^{1, \star}$ And Pascal Lazure $^{2}$
}

\author{
1 IFREMER, BP 21105, F- $44311 \mathrm{cdx}$ 03, Nantes, France \\ 2 IFREMER, BP 70, F- 29280, Plouzané, France \\ *Correspondence. e-mail : Pierre.Petitgas@ifremer.fr \\ phone : +33240374000 \\ fax: $\quad+33240374075$
}

\begin{abstract}
:
A growth and survival model in the early life stages was run along virtual drift trajectories tracked in a hydrodynamic model to simulate the annual recruitment process of anchovy (Engraulis encrasicolus) in the Bay of Biscay (NE Atlantic). These biophysical simulations concerning three different years were analysed in order to investigate the influence of environment and spawning dynamics on the survival of larvae and juveniles. The location of space-time survival windows revealed major environmental mechanisms involved in simulated recruitment variability at the different scales : retention of larvae and juveniles in favourable habitats over the shelf margins and turbulence effects. These mechanisms were related to the variations in wind direction and intensity during spring and summer. Survival was also variable according to the origin of the drift trajectories, i.e. spawning distribution in space and time. The spawning distribution that would maximise survival (according to the biophysical model) was compared with real spawning distribution (according to field surveys) on a seasonal scale, which revealed factors not considered in the biophysical model, including spawning behaviour of the different age classes. The variation of simulated survival according to spawning distribution was examined on a multi-annual scale, which revealed past and present stock structures. The interaction between population (influent on spawning) and environment (influent on survival) and its implications on recruitment and stock dynamics are discussed.
\end{abstract}

Keywords : Physical-biolological interactions, IBM, larval survival, recruitment, anchovy, Biscay, retention, turbulence. 


\section{INTRODUCTION}

Fish recruitment corresponds to the integration over a season and large oceanic areas of processes affecting the survival of a population of larvae and juveniles along their drift trajectories. The survival of these individuals results from the interaction between spawning dynamics (which determines the origin of the trajectories) and environmental variability (which determines transport and physical-biological interactions along the trajectories). The influence of environment on larval and juvenile survival has been conceptualised in general hypotheses, including food web match-mismatch (Cushing, 1975), stable ocean rupture (Lasker, 1978), physical dispersal (Sinclair, 1988), "triad" of oceanic conditions (Bakun, 1996). This led to look for correlation between series of environmental indices and fish recruitment. Following this type of research, the dependence of anchovy (Engraulis encrasicolus) recruitment on climate and hydrodynamic variations in the Bay of Biscay was studied by Borja et al. (1998) and Allain et al. (2001a).

In recent years, advances in numerical modelling allowed to model processes at the individual scale and use simulations to integrate individual-based processes at the population scale (e.g. Heath and Gallego, 1998). In particular, the influence of spawning distribution on transport towards nursery areas was investigated through simulation studies by Werner et al. (1996), Megrey et al. (1996), Heath and Gallego (1998), Bartsch and Coombs (2001, 2004), Mullon et al. (2003) and Parada et al. (2003). For anchovy in Biscay, a drift growth and survival model was developed (Allain et al., 2003a). The growth and survival model in the early life stages was simulated along virtual drift trajectories tracked in a hydrodynamic model to reproduce the annual recruitment process of anchovy in the Bay of Biscay. These biophysical simulations concerned three different years and were based on an average spawning dynamics model. The same spawning model was applied in each year. For each year of simulation, a recruitment index was calculated as the emergent result of 88440 simulations of biophysical interactions (4422 trajectories $\times 20$ 5-day periods). These simulations constituted a spatially-explicit and time-explicit data base as well as a source of information on recruitment dynamics.

Using this data base, the influence of environment on survival was investigated by locating the survival windows in space and time and analyzing transport processes at different scales. The dependence of survival on large-scale forcing physical processes (including wind regime) and small-scale biological mechanisms (related to food web dynamics) was examined. The influence of spawning population on survival was also investigated: spawning distribution in space and time was considered rather than abundance of spawners, as no stock-recruitment relationship was observed (ICES 2003). Maps of simulated larval survival based on different spawning distributions were estimated, which revealed major patterns in the interaction between the spawning population and its environment on seasonal and decennial scales. The implications for recruitment and stock structure and dynamics are then discussed.

\section{MATERIALS AND METHODS}

\subsection{The larval drift, growth and survival model}

The model was described in Allain et al. (2003a). Briefly, it consisted in different modules dedicated to spawning, transport, growth and survival. The drift module used a 3D circulation model developed for the entire Bay of Biscay (Allain et al., 2003b). Larval drift was modeled by virtual buoys passively transported by the average current in the 0-30 m surface layer. No diffusion was considered.

The growth module was statistically inferred by combining simulated 3D circulation model parameters to real biological data sampled at sea (larval and juvenile surveys performed in 1999). The otolith growth curves of sampled larvae and juveniles was regressed using GAMs on the time series of the simulated physical parameters along the drift trajectory that was associated to each individual fish. The parameters best explaining growth were age, temperature $(0-30 \mathrm{~m})$ and a stratification index (i.e. deficit of potential energy over the water column). The growth model estimated the average growth in response to environmental parameters as well as the statistical distribution of the residuals.

It was therefore possible to estimate a survival index defined as the probability for the growth rate at a given age to be higher than a threshold, under a growth-dependent mortality hypothesis consistent with field observations (Allain et al., 2003b). The threshold was defined as the minimal growth rate 
observed at this age among the sampled juveniles older than 100 days post-hatch, considered as survivors (Allain et al., 2003a). The survival module allowed for the estimation of a survival index at each time step along a given individual drift trajectory. The multiplication of all the survival probabilities along the drift trajectory permitted to estimate an overall survival probability for each individual during its early life (first 100 days post-hatch).

The spawning module represented the average space-time spawning dynamics (i.e. the average seasonal evolution of egg maps and fecundity ogive: Allain et al., 2003a). It was built by combining literature knowledge with egg survey results. Each spawning area (14 nm $x 14 \mathrm{~nm}$ square) produced eggs during the season according to (a) an average egg abundance index derived from annual surveys and (b) a spawning ogive derived from repetitive monthly surveys. Ogive peak timing varied from area to area according to the known general spawning pattern (Motos et al., 1996). The spawning index Is for each space-time unit was in percent of average annual egg production.

For each year of simulation, virtual buoys were released each week from April to August (22 weeks) from a spawning grid (201 points) and tracked for 105 days in the hydrodynamic model. The total survival probability along each buoy trajectory, i.e. survival rate $\mathrm{Sr}$, was estimated. A survival index $\mathrm{Si}$ was then calculated for each subcohort by multiplying the spawning index Is corresponding to the space-time origin of its trajectory by the survival rate $\mathrm{Sr}$ estimated along its trajectory. $\mathrm{Sr}$ was a potential survival index while Si was a realised survival index given the spawning distribution.

\subsection{Survival variability in space and time}

Campana and Jones (1992) and Mullin (1993) proposed to analyze recruitment dynamics by studying the characteristics of the survivors. Here, we located and characterized the survival windows in space and time, using the survival index Si for each simulated subcohort of larvae and juveniles. The temporal pattern in survival was examined by summing the simulated survival indices over space for each week of the spawning period. The spatial pattern was examined by summing over time the survival indices for each point of the simulation grid.

\subsection{Survival mechanisms related to habitat, transport and wind regime}

The relation between survival and transport was explored using the previous analysis and maps of the drift trajectories of the virtual buoys released from the main spawning grounds over the entire season (i.e. Gironde estuary and Capbreton area: Motos et al., 1996; Allain et al., 2004). The interaction between the drift trajectories and the pattern in the simulated fields of temperature and stratification (which were forcing variables of the growth and survival model) was explored.

Transport in the upper layer across the Bay of Biscay at the scale of several months was largely related to the wind regime (Lazure and Jégou, 1998; Allain et al., 2003b). Therefore the relation between the wind regime in spring and summer and the transport scheme observed was investigated using wind observations made by Météo-France at Cap-Ferret semaphore $\left(45^{\circ} \mathrm{N}\right.$ along French coast). The influence of wind-induced turbulence on survival (Lasker, 1978; Mackenzie, 2000; Gallego et al., 1996; Sundby, 1997; Bergeron, 2000; Allain et al., 2001) was examined by comparing the time series evolution of wind intensity (measured by Météo-France), surface water temperature $(0-30 \mathrm{~m})$ and simulated survival indices (by 5-day periods).

\subsection{Comparison between observed spawning distribution and potential survival distribution}

The survival rate $\mathrm{Sr}$ estimated for each subcohort over its trajectory (Allain et al., 2004) depended on the simulated environment encountered along each drift trajectory, hence was considered as an index of potential survival. Potential survival at 100 days post-hatch was mapped by locating the $\mathrm{Sr}$ values at the points of the virtual buoys releases (origin of trajectories), for each week in the spawning season. The origins of the subcohort trajectories with high potential survival were expected to correspond to favorable spawning areas according to the biophysical model. Agreement in the spatial patterns of the observed spawning distribution and the potential survival distribution was visually tested for. Maps of potential survival were compared to the average spawning distributions observed at the beginning (April-May), peak (June) and end (July-August) of the spawning season (average spawning model). 


\subsection{Variation in the spatial distribution of potential survival on a multi-annual scale}

An annual potential survival index was calculated for each point of the grid by summing the survival rates $\mathrm{Sr}$ estimated for all the trajectories released from this point over the reproductive season. Then a map representing the inter-annual variability in potential survival was produced by the following procedure. For each point of the grid, a vector $v$ of 3 elements was defined containing the year numbers ordered by decreasing order of annual potential survival (for example, $v=(1997,1999,1998)$ in the case where survival was high in 1997, medium in 1999 and low in 1998). Six different vector values ( $3 \times 2 \times 1)$ were possible for $v$. The values of the vectors $v$ were then mapped (one value per grid point).

\section{RESULTS}

\subsection{Survival variability in space and time}

According to the biophysical model (Figs. 1 and 2), high recruitment observed in 1997 corresponded to high survival of late spawning in the southern part of the Bay of Biscay (especially the Gironde area). In contrast low recruitment in 1998 corresponded to early spawning. Medium recruitment in 1999 corresponded to peak spawning over the central part of the bay.

Subcohorts with high survival indices at the age of 100 days post-hatch were numerous and located over the shelf in 1997, scarce and located off the shelf break in 1998 and rather numerous and located both over the shelf and in oceanic waters in the southern part of the bay in 1999 (Fig. 3). Over the three years of simulation, the higher survival indices were mostly located on the outer shelf and over the shelf margins between $45^{\circ} \mathrm{N}$ and $46^{\circ} \mathrm{N}$.

\subsection{Influence of transport and habitat on survival}

The drift trajectories showed important retention over the shelf margins in 1997, advection towards oceanic waters in 1998 and an intermediate situation in 1999 (Figs. 3 and 4). A relationship between the survival index at 100 days post-hatch and the duration of transport in waters over the shelf (bottom depth $<1000 \mathrm{~m}$ ) was evidenced (Fig. 5) over the three years of simulation. Oceanic waters (bottom depth $>1000 \mathrm{~m}$ ) were more stratified and slightly warmer in the upper $30 \mathrm{~m}$ than waters over the shelf and shelf break (Fig. 6), which influenced growth hence survival in our model.

\subsection{Influence of wind regime on transport}

Transport from the main spawning grounds (Fig. 4) during the years 1997 to 1999, which resulted in the subcohort distributions illustrated on Fig. 3, could be schematically summarized in three transport regimes (Fig. 7), and related to wind regime variations. Schemes 7a,b,c were dominant respectively in 1997, 1998 and 1999. The vectorial sum of the wind from 1 May to 30 September at Cap-Ferret semaphore for the years 1997-99 showed a common dominant NW wind regime (Fig. 8) in spring and summer but a prevalence of westerlies in 1998 in comparison to 1997 and 1999. Dominant westerlies in 1998 were associated with an advective transport (Fig. 7b) towards oceanic waters off the shelf.

\subsection{Influence of wind induced turbulence on larval mortality}

The wind measurements from 1 May to 30 September at Cap-Ferret semaphore for the years 1997-99 showed no major turbulence peak (Fig. 9) in comparison to those observed over the last 15 years (Allain et al., 2001). The only noticeable turbulent peak occurred in June 1997 and a temporary drop in the simulated temperature (in the upper $30 \mathrm{~m}$ ) was observed. The survival index at 5 days post-hatch also dropped but the influence of the temperature drop was no longer noticeable on the survival at 30 days post hatch (Fig. 9). Hence the major impact of the wind regime on survival in the years 1997-99 concerned transport (advection vs. retention of the larvae over the shelf) rather than turbulence, according to the biophysical model. 


\subsection{Comparison between observed spawning distribution and potential survival distribution}

The comparison between average spawning distribution (according to field observations) and potential survival distribution (i.e optimal spawning distribution according to the biophysical model) at the beginning (April-May), peak (June) and end (July-August) of the spawning season showed convergent and divergent elements (Fig. 10). The common points were : moderate spawning in SE Biscay in April-May, peak spawning from 45 to $46^{\circ} \mathrm{N}$ in June, low to moderate spawning in the northern part of the bay in July-August. The favourable spawning areas according to the biophysical model showed a later, more northerly and less coastal distribution than the observed one.

\subsection{Variation in the spatial distribution of potential survival on a multi-annual scale}

The map of the $v$ vector values (one value per grid point corresponding to the ordering of the years by decreasing order of the survival index) revealed a coherent geographical pattern (Fig. 11) with three distinct areas. A first area A (diamonds and circles on the figure) extended over most of the French shelf with sub-areas from the SE corner to the NW. A second area B corresponded to the Spanish shelf. A third area $\mathrm{C}$ extended over oceanic areas in the south and the external part of the bay in the north. This pattern, which delimited distinct regions according to the biophysical model, suggested that spawning distribution had a noticeable influence on larval survival. The areas delimited on figure 11 could be compared with present (Motos et al., 1996) and past (Junquera, 1986) real spawning distributions (see Discussion).

\section{DISCUSSION}

The biophysical, individual-based model of larval drift, growth and survival represented a valuable tool for investigating the influence on recruitment of (i) physical-biological interaction mechanisms and (ii) spawning dynamics at different time and space scales. The study highlighted the major interaction that took place in the years 1997-99 between drift trajectories (forced by the wind regime) and habitat physical characteristics (shelf and oceanic waters). The biophysical model formulated physical forcing on growth at individual scale only. Physical forcing parameters where understood as indicators of physical-biological processes occurring in the plankton and influent on larval survival. The simulations which performed the spatio-temporal integration at population scale evidenced the interaction between transport and habitat characteristics (i.e. importance of retention over the shelf margins) in determining larval growth and survival.

Regional scale correlation between series of environmental indices and anchovy recruitment estimates had been evidenced in previous studies (Borja et al., 1998; Allain et al., 2001). It was therefore of interest to understand how the biophysical model responded to the regional scale forcing. The stock before the early 1970s extended largely on the Spanish coast with other spawning grounds than the present ones, which are concentrated in the SE corner of Biscay only (Junquera, 1986). It was therefore also of interest to understand the difference in potential survival between past and present spawning grounds under present environmental conditions. These aspects are now discussed.

\subsection{Biological processes related to the physical parameters influent on growth.}

Stratification index and temperature (i.e. the forcing physical variables of the growth model) could be considered as crude indicators of the type of habitat encountered by subcohorts during their early life. Stratification clearly differentiated shelf from oceanic habitats in the model simulations (Fig. 6). Growth-related survival along the drift trajectories estimated by the biophysical model was enhanced in warm and moderately stratified waters (Allain et al., 2003a). In the simulations, low temperature limited growth during the first part of the trajectories, at the beginning of the season (April-May) and for younger stages. In contrast, high stratification limited growth for subcohorts transported off the shelf in open ocean waters in summer. Food-web processes are in general related to the vertical structure of the sea (Mann and Lazier, 1991) of which temperature and stratification are indicators. Moderately stratified waters over the shelf may be enriched by productive systems in nearby mixed areas (coast, shelf edge) while strongly stratified waters in the open ocean may be poor. Waters over the shelf margins might correspond to a favourable trade-off between enrichment, concentration and retention (processes of the 'triad' defined by Bakun, 1996). Open ocean waters might be detrimental to larvae 
and juveniles because of a lower prey abundance, lower encounter rates with prey due to high stratification (Sundby 1997) and higher abundance of pelagic predators (Bakun 1996). Further studies would be necessary to explicit the biological mechanisms underlying the simulations results.

\subsection{Influence of wind regime on retention and upwelling}

Circulation in the southern Bay of Biscay is relatively complex due to the bathymetry and the shape of coast and shelf break. It is influenced by tide and salinity gradients at the time scale of days to weeks and mainly related to wind at the scale of several months (Lazure and Jégou, 1998 ; Allain et al. 2001b). Westerlies were dominant in 1998 (Fig. 8) and associated with an advective transport pattern towards oceanic waters (Fig. 7) according to the hydrodynamic simulations. Westerlies may generate a drift towards the south in the Ekman layer thus favouring advection towards oceanic waters of subcohorts originating from spawning areas off Gironde. Along the north coast of Spain, the usual summer westward current of surface waters towards Galicia and outside the bay (Cabanas et al., 2003; Fig. 4 and 7) may be slowed down by strong or prolonged westerlies (Gil and Sanchez, 2003), resulting in an advection off the shelf of the larvae born on the French shelf (Fig. 7b). On the opposite, weak to moderate north-easterlies would be favorable to retention on the French shelf and hence survival (Fig. 7a).

Borja et al. (1998) and Allain et al. (2001a) showed a positive relationship between the frequence of weak upwelling events due to north-easterly winds and anchovy recruitment by regional scale correlation analysis. Upwelling and retention processes would occur for the same wind regimes. Anchovy recruitment in the Bay of Biscay could be enhanced by north-easterly winds from March to September, through two distinct mechanisms: enrichment related to upwelling events especially from March to May and transport related to retention of larvae and juveniles in favorable areas over the French shelf from May to September.

\subsection{Influence of wind-induced turbulence on survival}

The negative effect of turbulence caused by strong winds on anchovy larval feeding and survival was shown by Lasker (1978) and Peterman and Bradford (1987) in the California Current and observed by Bergeron (2000) in the Bay of Biscay. Allain et al. (2001a) evidenced that anchovy recruitment was negatively influenced by stratification breakdown events related to strong winds observed for 1-4 day periods in early summer (in 1987, 1988, 1990 and 2001). No such turbulence peak was observed during the period of simulations (1997-1999). Nonetheless the strongest winds in the period 19971999 were observed to cause short-term drops in surface temperature $(0-30 \mathrm{~m})$ along the drift trajectories (Fig. 9). The effect on the stratification index was less perceivable (not illustrated). The only noticeable turbulent peak occurred in late June 1997 and the subsequent drop in temperature led to a decrease in the simulated growth and survival rate of young larvae (5 days post hatch) compared to the same period in 1998 and 1999 (Fig. 9). This difference was compensated after 30 days post hatch by better survival due to higher retention in 1997, hence had no significant effect on predicted recruitment.

Strong winds in the Bay of Biscay are generally south-westerlies and westerlies, which would have a negative influence on retention too (see previous paragraph). Thus intense gale winds are expected to affect larval growth in the biophysical model via a turbulence-induced temperature decrease as well as a wind-induced transport in unfavourable areas leading to low survival. For the simulated years 199799, the biophysical model was more sensitive to the effects of wind on transport than on turbulence. The effect of wind intensity on turbulence may be more influent above a certain threshold, depending on wind speed and gale duration. This threshold would be higher than the one observed in 1997 and lower than the ones observed in stratification breakdown events in 1987, 1988, 1990 and 2001. Hence such a turbulence level would require winds stronger than 14-15 m.s ${ }^{-1}$ for 2 days or stronger than 12$13 \mathrm{~m} . \mathrm{s}^{-1}$ for 4 days. These values are comparable with the value of $15-16 \mathrm{~m} \cdot \mathrm{s}^{-1}$ above which instantaneous wind intensity was reported to be detrimental to larval survival by Mackenzie (2000), Gallego et al. (1996) and Sundby (1997).

\subsection{Spawning distribution: best for adults or larval survival?}

The spawning distribution with greatest potential larval survival according to the biophysical model was less coastal and more northerly than the observed spawning distribution. This was obvious at peak spawning (June, Fig. 10) : spawning locations with best larval survival would concentrate over the central part of the shelf (model prediction) rather than off Gironde where eggs were observed. The 
central part of the shelf was a strong retention area according to hydrodynamic simulations (Fig. 12): the trajectories of the virtual buoys released from this area all remained over the shelf in a gyre-like structure, which resulted in higher predicted survival. The differences between the observed and optimal spawning distributions according to the biophysical model may either be due to a bias in the modelling (systematic overestimation of retention over the central shelf) or to elements absent from the model (biological processes weakly or not related to the physical variables considered in the model). Being an indeterminate batch spawner, adult anchovies require sufficient food intake to continue spawning (Hunter and Roderick, 1981). Hence, the egg distribution may reflect a compromise between locations favourable for adult nutrition and spawning and locations favourable for larval survival.

The major areas where spawning concentrations were observed were under the influence of Gironde and Adour river plumes (Fig. 10). River plumes represent major spawning areas for anchovy in the Bay of Biscay (Motos et al., 1996) and in other regions also (Garcia and Palomera, 1996). However anchovy recruitment success was apparently not related to river plume variations (Allain et al., 2001) and larval growth was apparently not significantly related to salinity (Allain et al., 2003a). River plumes are characterized by the importance of small-size zooplankton $(<100 \mu \mathrm{m})$ related to the microbial loop (Garcia and Palomera, 1996) developing in spring and summer (Hartmann et al., 1998) subsequently to winter phytoplanktonic blooms (Labry et al., 2001). This plankton food web structure may be favorable to the feeding of larvae (Garcia and Palomera, 1996 ; Hartmann et al., 1998) and/or young adults: river plumes represent 'post-nursery' areas where one-year old small pelagics (anchovy, sprat, mackerel) concentrate in spring (Massé, 1996). The concentration of anchovy spawning in river plumes may also be related to population structure. Age 1 fish represent 70 to $80 \%$ of the stock (ICES, 2003) which predominantly spawn in coastal river plumes, whereas age $2+$ fish tend to spawn in the outer part of the shelf and shelf break (Motos et al., 1996). The plume habitat might better support the energetic demand of young spawning fish (Hunter and Roderick, 1981).

\subsection{Spawning distribution and recruitment}

Figure 11 shows the possible influence of the spawning stock on recruitment, not through the number of spawners (i.e. stock-recruitment relationship) but through the spatial distribution of spawning. For example, spawning along the north coast of Spain would have resulted in high recruitment in 1998, intermediate in 1999 and low in 1997 according to the biophysical model, i.e. in opposition to the real recruitment variations observed (spawning being mainly located along the French coast). This would suggest that there is neither good nor bad environment but an interaction between the spawning strategy on particular habitats and the hydro-climate induced survival. Rather than correlation between series of environmental and recruitment indices, the understanding of such interaction should be sought. A tool like the present biophysical model is helpful for doing so. On Fig. 11, the area A corresponded to the real present spawning area of the population. It contained two subareas, the main peak spawning grounds in SE Biscay (diamonds on Fig. 11) and the northerly extension of spawning at the end of the season (circles on Fig. 11). This would suggest that because of the present spawning area, anchovy recruitment would be under the influence of summer stratification and temperature (as formulated in the biophysical model) as well as a circulation regime characterized by a gyre centered over the French shelf (Fig. 12). The area B (Spanish shelf, circles with a cross on Fig. 11) corresponded to past important spawning grounds (Junquera, 1986), which are presently marginal. Inter-annual variability in simulated recruitment $(v=(1998,1999,1997))$ in area B was opposite to that in the peak spawning area of area A. In the 1960s a much larger anchovy stock (annual captures were 2 to 5 times higher than present ones) was distributed all along the Spanish coast from Galicia to Southern France (Junquera, 1986). A stock distributed over both Spanish and French shelves would theoretically benefit from their opposite hence complementary environmental variations according to the biophysical simulations. Simulations over a longer series of years would enable to better characterize the interaction between spawning dynamics and environment.

\section{CONCLUSION}

The simulation studies showed that a biophysical, individual-based model of growth and survival in fish early life stages represented a valuable tool for investigating the influence on recruitment of (i) physical-biological interaction mechanisms and (ii) spawning dynamics at different time and space scales. A next step would consist in expliciting the small-scale biological mechanisms related to the physical processes apparently influent on recruitment (stratification, shelf edge processes, upwelling) 
and including spawning physiology of the different age classes and inter-annual variability in the spawning module.

\section{ACKNOWLEDGEMENTS}

This study was part of a Ph.D work which was co-financed by IFREMER, Région Pays de la Loire and Comité National des Pêches Maritimes (Commission de l'anchois et de la sardine). It contributed to the project FOREVAR (environmental forcing and stock variability) affiliated to GLOBEC. 


\section{REFERENCES}

Allain G., Petitgas P., Lazure P. and Grellier P. (2001) The influence of mesoscale ocean processes on anchovy (Engraulis encrasicolus) recruitment in the Bay of Biscay estimated with a threedimensional hydrodynamic model. Fish. Oceanogr. 10: 151-163.

Allain G., Petitgas P., Lazure P. and Grellier P. (2003a) Stochastic bio-physical modelling of anchovy larval growth and survival in the Bay of Biscay and its use for recruitment prediction. ICES CM 2003/P:25.

Allain G., Petitgas P., Grellier P. and Lazure P. (2003b) The selection process from larval to juvenile stages of anchovy in the Bay of Biscay investigated by Lagrangian simulations and comparative otolith growth. Fish. Oceanogr. 12(4/5): 407-418.

Allain G., Petitgas P. and Lazure P. (2004) Use of a biophysical larval drift growth and survival model to explore the interaction between a stock and its environment: anchovy recruitment in Biscay. ICES CM 2004/J:14.

Bakun A. (1996) Patterns in the Ocean : Ocean Processes and Marine Population Dynamics. San Diego: University of California Sea Grant.

Bartsch J. and Coombs S.H. (2001) An individual-based growth and transport model of the early lifehistory stages of mackerel (Scomber scombrus) in the eastern North Atlantic. Ecological Modelling 138: $127-141$.

Bartsch J., and Coombs S.H. (2004) An individual-based model of the early life history of mackerel (Scomber scombrus) in the eastern North Atlantic, simulating transport, growth and mortality. Fish. Oceanogr. 13: 365-379.

Bergeron J.-P. (2000) Effects of strong winds on the nutritional condition of anchovy (Engraulis encrasicolus) larvae in the Bay of Biscay, NE Atlantic, as inferred from an early field application of the DNA/C index. ICES J. Mar. Sci. 57: 249-255.

Borja A., Uriarte A., Egaña J., Motos L. and Valencia V. (1998) Relationships between anchovy (Engraulis encrasicolus) recruitment and environment in the Bay of Biscay. Fish. Oceanogr. 7: 375-380.

Cabanas J., Lavín A., García M., Gonzalez-Pola C. and Pérez E. (2003) Oceanographic variability in the northern shelf of Iberian Peninsula, 1990-1999. ICES Mar. Sci. Symp. 219: 71-79.

Campana S.E. and Jones C.M. (1992) Analysis of otolith microstructure data. Can. Spec. Publ. Fish. Aquat. Sci. 117: 73-100.

Cushing D.H. (1975) Marine ecology and fisheries. Cambridge University Press, Cambridge UK, 215 pp.

Gallego A., Heath M.R., Mackenzie E. and Cargill L.H. (1996) Environmentally induced short-term variability in the growth rates of larval herring. Mar. Ecol. Prog. Ser. 137: 11-23.

Garcia A. and Palomera I. (1996) Anchovy early life history and its relation to its surrounding environment in the Western Mediterranean basin. Sci. Mar. 60 (Supl.2): 155-166.

Gil J., and Sánchez F. (2003) Aspects concerning the occurrence of summer upwelling along the southern Bay of Biscay during 1993-2000. ICES Mar. Sci. Symp. 219: 337-339.

Hartmann H., Nejstgaard J., and Thivent V. (1998) Utilisation du microzooplancton par leurs prédateurs: larves d'anchois et copépodes. Rapport final contrat universitaire 985511114, IFREMER Nantes, 55p

Heath M. and Gallego A. (1998) Bio-physical modelling of the early life stages of haddock, Malanogrammus aeglefinus, in the North Sea, Fish. Oceanogr. 7(2): 110-125.

Hunter J. and Roderick L. (1981) The spawning energetics of female northern anchovy, Engraulis mordax. Fish. Bull. 79: 215-230.

ICES (2003) Report of the working group on the assessment of mackerel, horse mackerel, sardine and anchovy. ICES CM 2003/ACFM:06 
Junquera S. (1986) Changes in the anchovy fishery of the Bay of Biscay in relation to climatic and oceanographic variations in the north atlantic. Int. Symp. Long Term Changes in Marine Fish Populations, Wyatt T. and Larrañeta M. (Eds), IEO, Vigo.

Labry C., Herbland A., Delmas D., Laborde P., Lazure P., Froidefond J-M., Jégou A.M. and Sautour B. (2001) Initiation of winter phytoplankton blooms within the Gironde plume waters in the bay of biscay. Mar Ecol. Prog. Ser. 212: 117-130.

Lasker R. (1978) The relation between oceanographic conditions and larval anchovy food in the California current : identification of factors contributing to recruitment failure. Rapp. P.-V. Réun. Cons. Int. Explor. Mer. 173: 212-230.

Lazure P., and Jégou A.-M. (1998) 3D modelling of seasonal evolution of Loire and Gironde plumes on Biscay Bay continentel shelf. Oceanologica Acta 21: 165-177.

MacKenzie B. (2000) Turbulence, larval fish ecology and fisheries recruitment: a review of field studies. Oceanologica Acta 23: 357-375.

Mann K., and Lazier J. (1991) Dynamics of Marine Ecosystems: Biological-Physical Interactions in the Oceans. Blackwell Science, Boston, 459p.

Massé J. (1996) Acoustic observations in the bay of Biscay: schooling, vertical distribution, species assemblages and behaviour. Sci. Mar. 60 (Suppl.2): 227-234.

Megrey B., Hollowed A., Hare S., Macklin A. and Stabeno P. (1996) Contributions of FOCl research to forecasts of year class strength of walleye pollock in Shelikof Strait, Alaska. Fish. Oceanogr. 5 (Suppl.1): 189-203.

Motos L., Uriarte A. and Valencia V. (1996) The spawning environment of the Bay of Biscay anchovy (Engraulis encrasicolus, L.). Sci. Mar. 60 (Suppl.2): 117-140.

Mullin M. (1993) Webs and scales : physical and ecological processes in marine fish recruitment. Washington Sea Grant Program, University of Washington Press, Seattle. 135 pp.

Mullon C., Fréon P., Parada C., Van der Lingen C. and Huggett J. (2003) From particles to individuals: modelling the early stages of anchovy in the southern Benguela. Fish. Oceanogr. 12 (4/8): 396406.

Parada C., Van der Lingen C., Mullon C., and Penven P. (2003) The effect of buoyancy on the transport of anchuvy eggs from spawning to nursery grounds in the Southern Benguela. Fish. Oceanogr. 12:1-15.

Peterman R.M. and Bradford M.J. (1987) Wind speed index and mortality rate of a marine fish, the northern anchovy (Engraulis mordax). Science 235: 354-356.

Sinclair M. (1988) Marine populations : an Essay on Population Regulation and Speciation. Seattle, WA: University of Washington Press, $252 \mathrm{pp}$.

Sundby S. (1997) Turbulence and ichthyoplankton : influence on vertical distributions and encounter rates. Sci. Mar. 61 (Suppl. 1): 159-176.

Werner F.E., Page F.H., Lynch D.R., Loder J.W., Lough R.G., Perry R.I., Greenberg D.D. and Sinclair M.M. (1996) Influences of mean advection and simple behavior on the distribution of cod and haddock early life stages on Georges Bank. Fish. Oceanogr. 2: 43-64. 


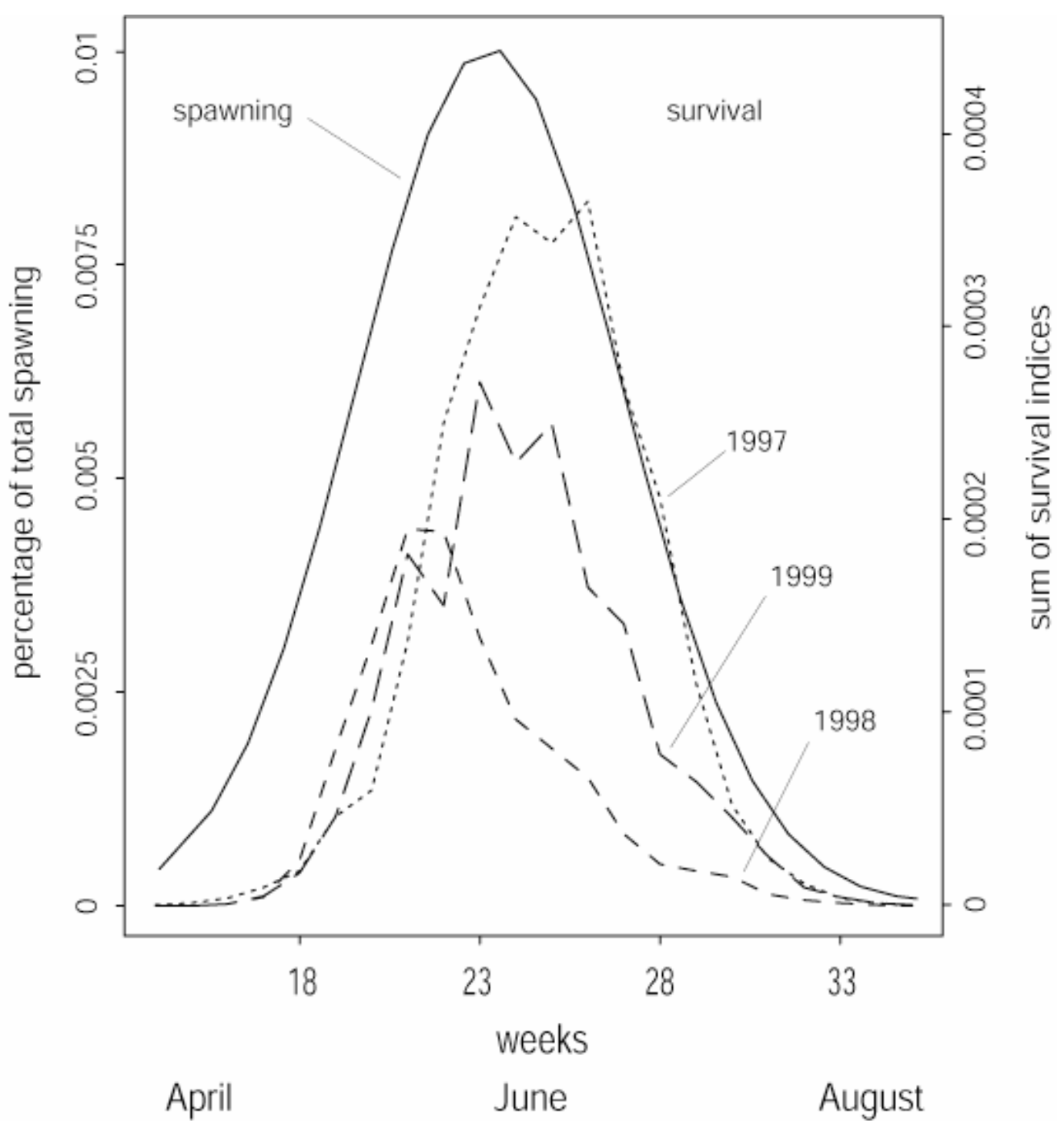

Figure 1: Spawning ogive (average model based on field surveys, solid line) and larval survival windows (biophysical simulation results, dotted lines). 
1997

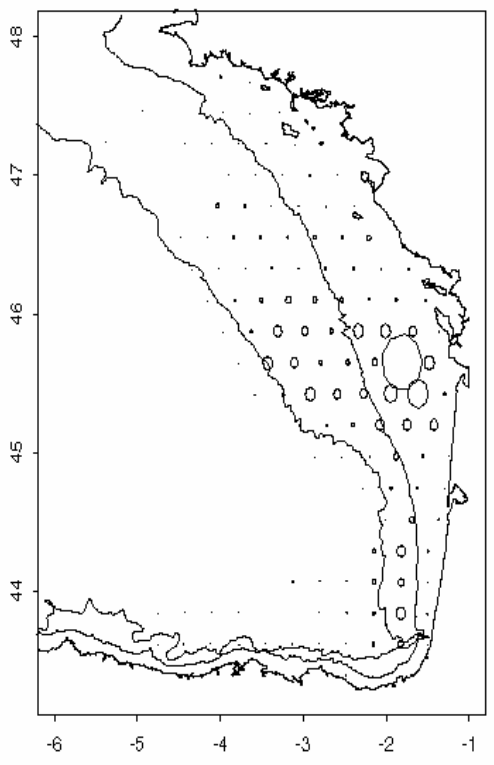

1998

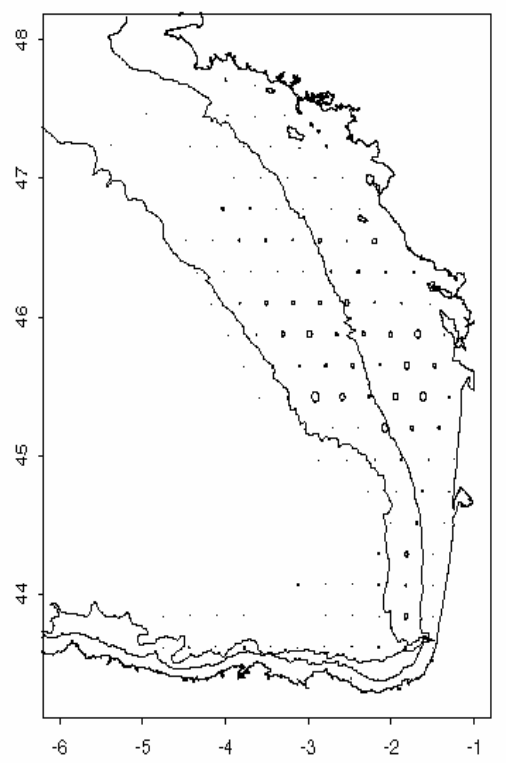

1999

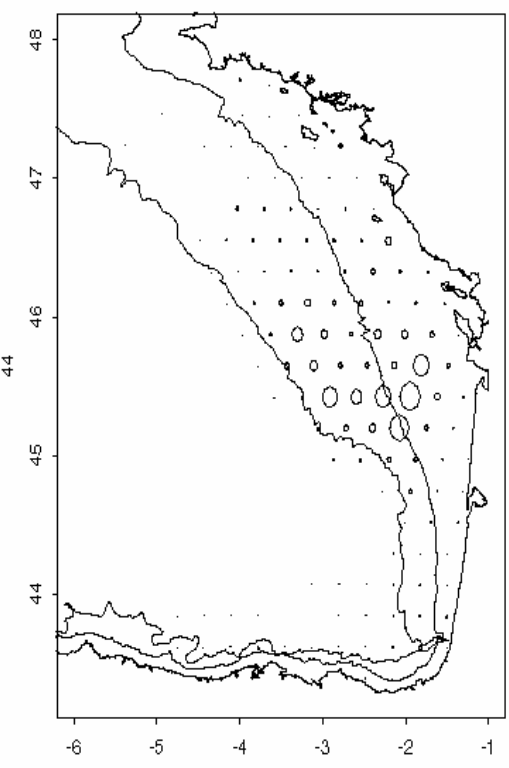

Figure 2: Annual larval survival mapped at origin of the trajectories (spawning locations) for the years 1997, 1998 and 1999. The circle radius at each point of the spawning grid is proportional to the sum over the spawning season of the survival indices of all the subcohorts originating from this point. Survival is estimated on the 100 days post hatch for all the subcohorts born from April to August.

1997

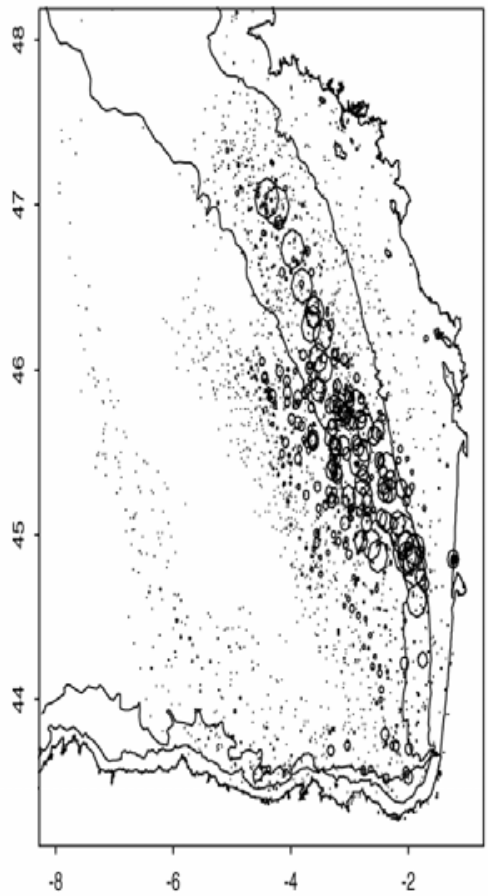

1998

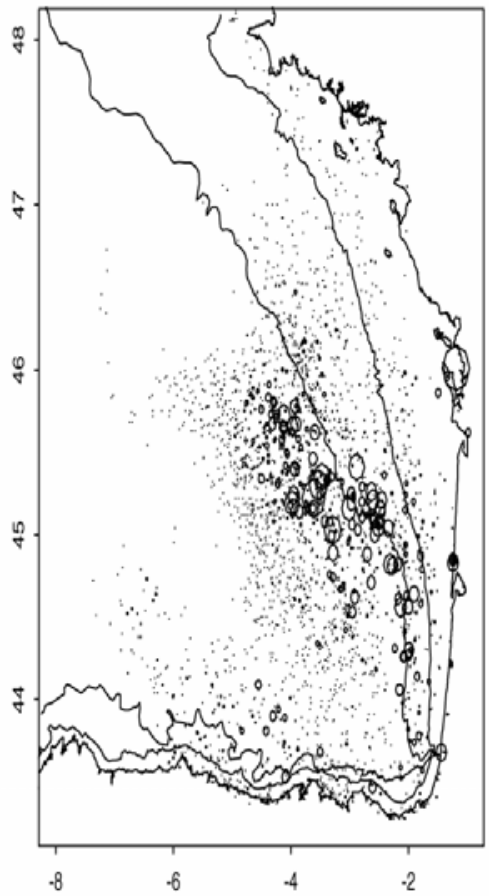

1999

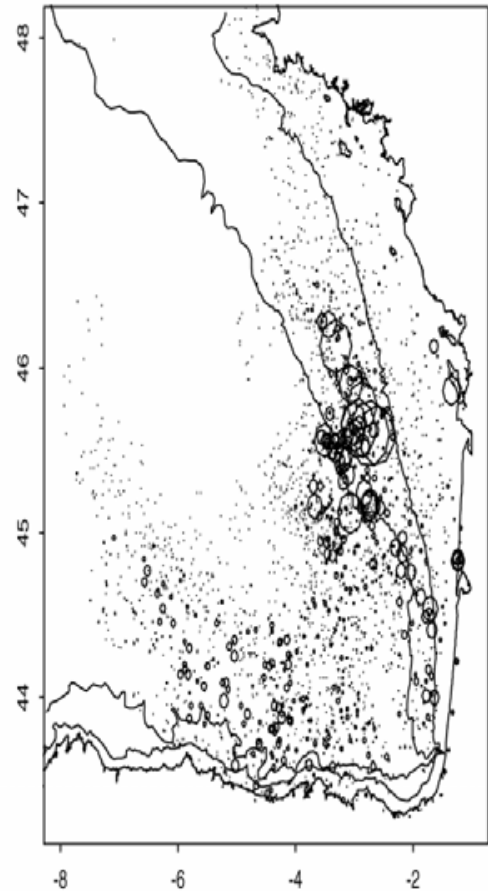

Figure 3: Annual larval survival mapped at end of the trajectories for the years 1997, 1998 and 1999. The circles are centred on the position of the subcohorts at the age of 100 days post hatch. Each circle radius is proportional to the survival probability integrated along the trajectory (simulation result) multiplied by the spawning index (estimated egg abundance) at the trajectory origin. Survival is estimated on the 100 days post hatch for all the subcohorts born from April to August. 


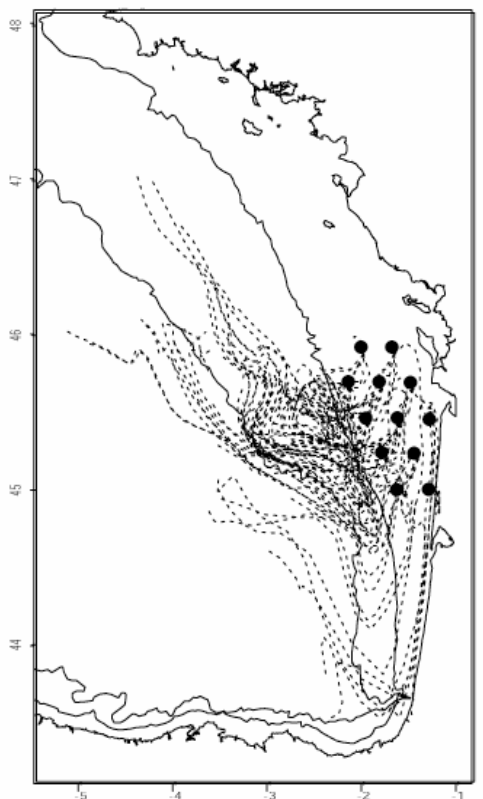

1997

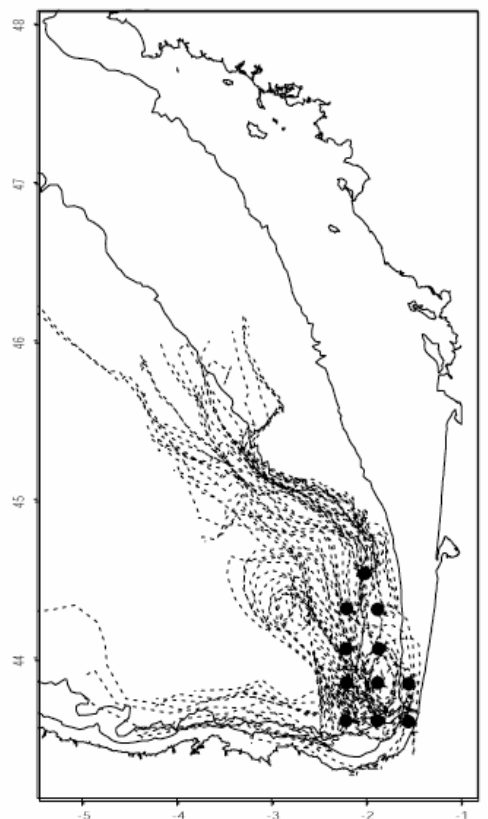

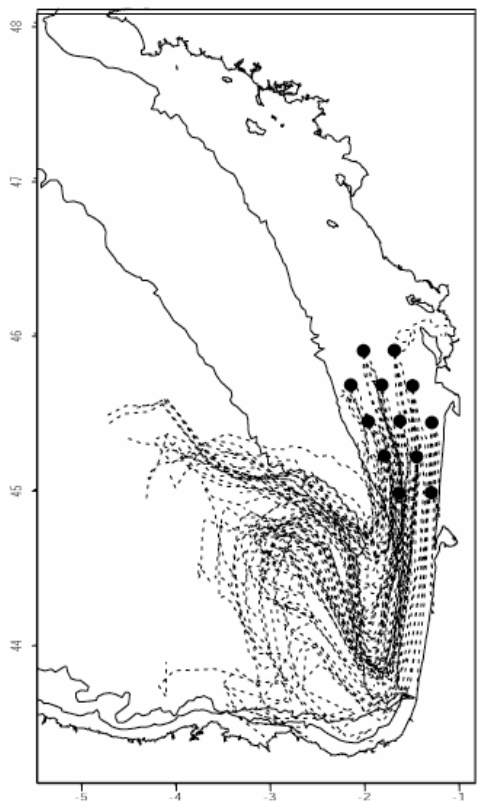

1998

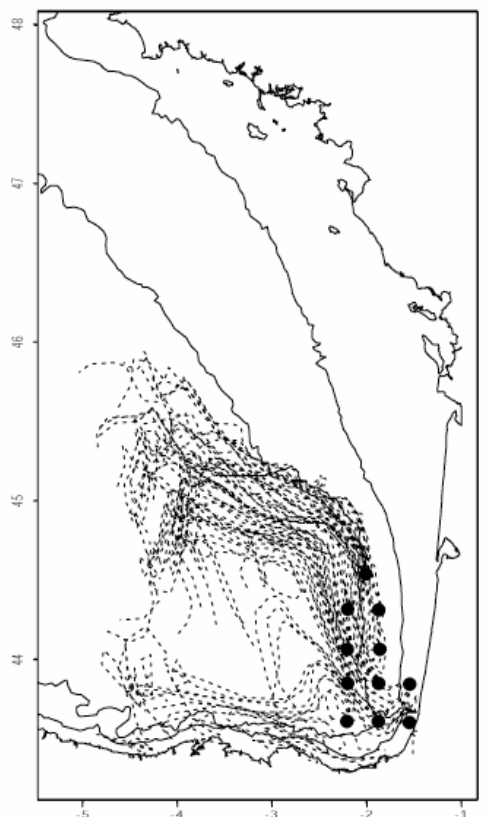

1999

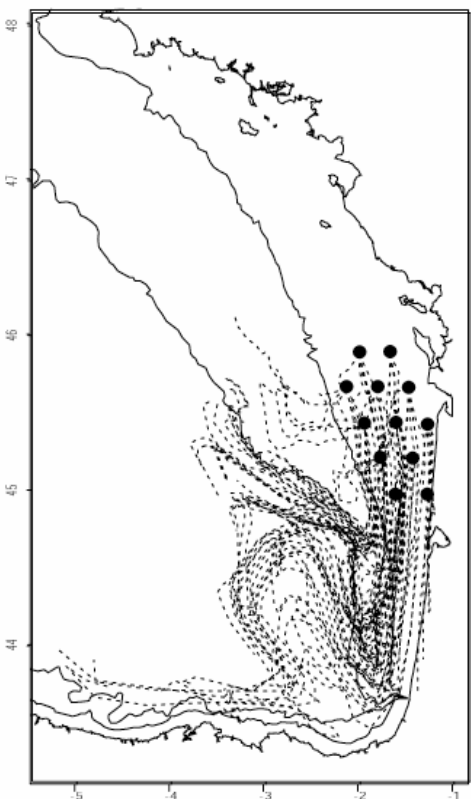

1999

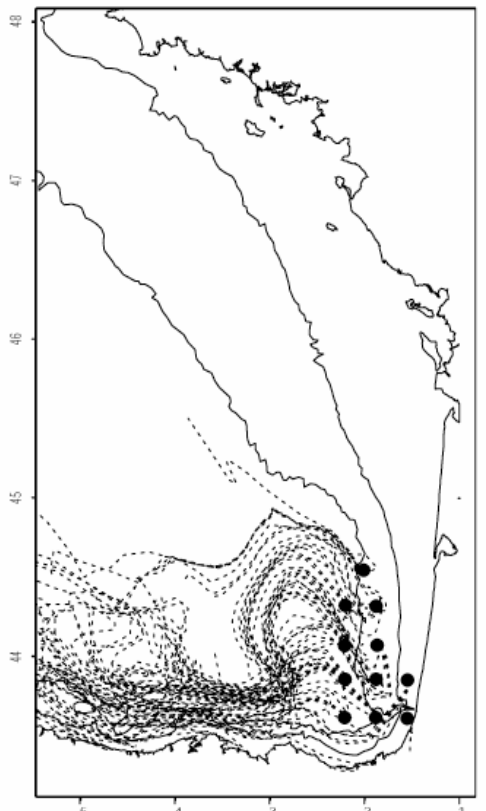

Figure 4: Transport from the main spawning grounds (top : Gironde area, bottom : Capbreton area) over the entire spawning season. The black dots represent the points of weekly releases i.e. the origins of the trajectories. The dashed lines represent the drift trajectories from spawning until the age of 100 days post hatch. 


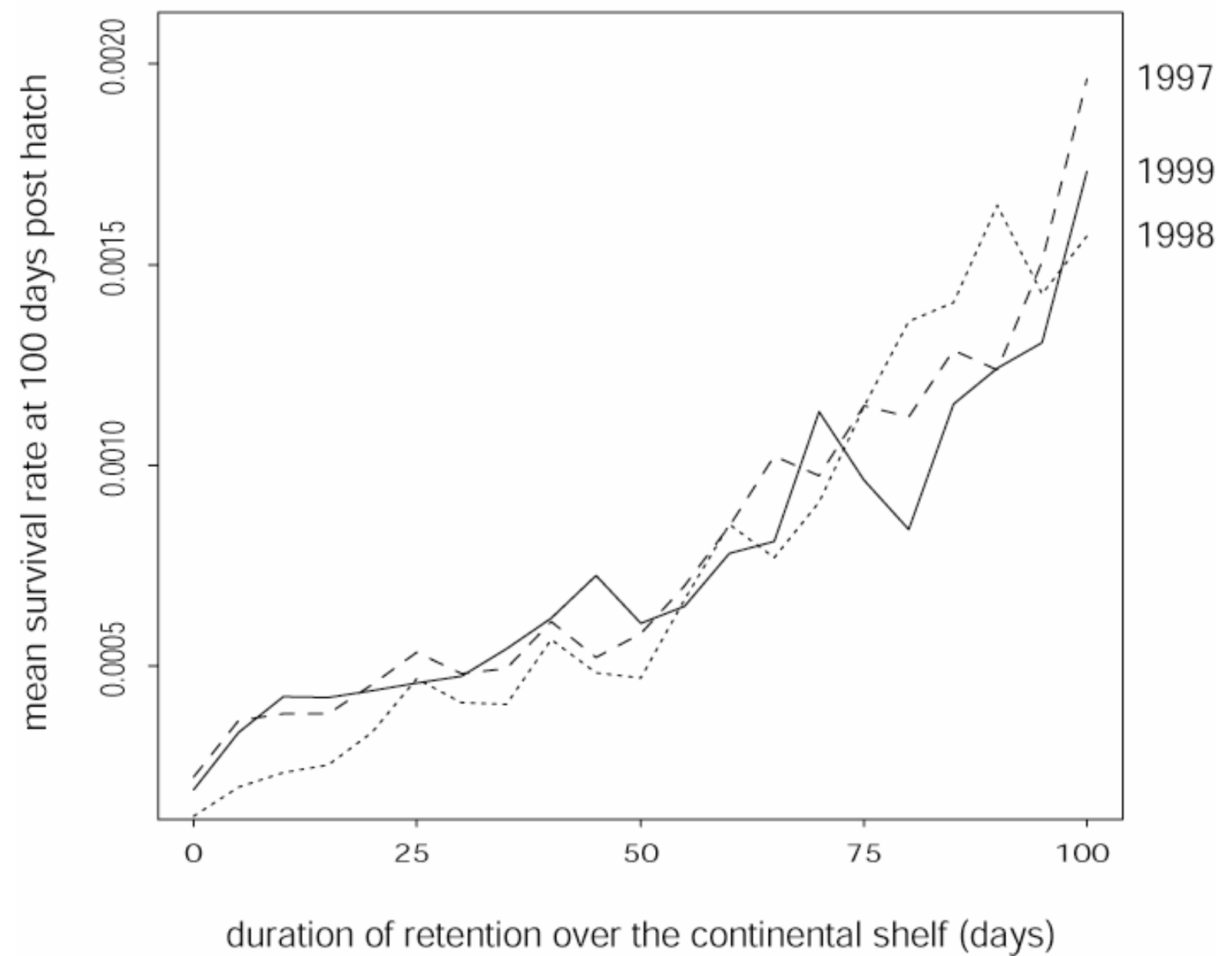

Figure 5: Mean survival rate along the trajectories as a function of the number of days of drift over the shelf and shelf break (bottom depth $<1000 \mathrm{~m}$ ). 


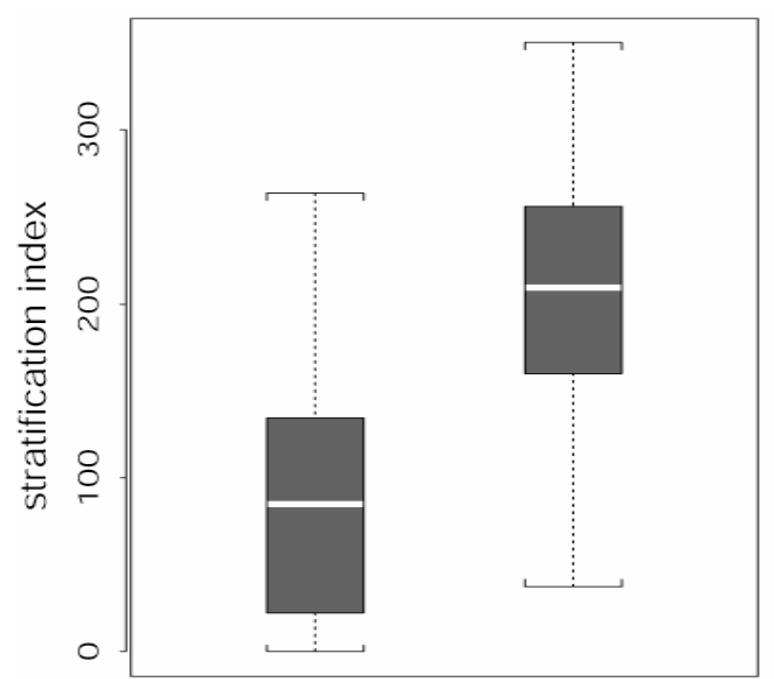

(a)

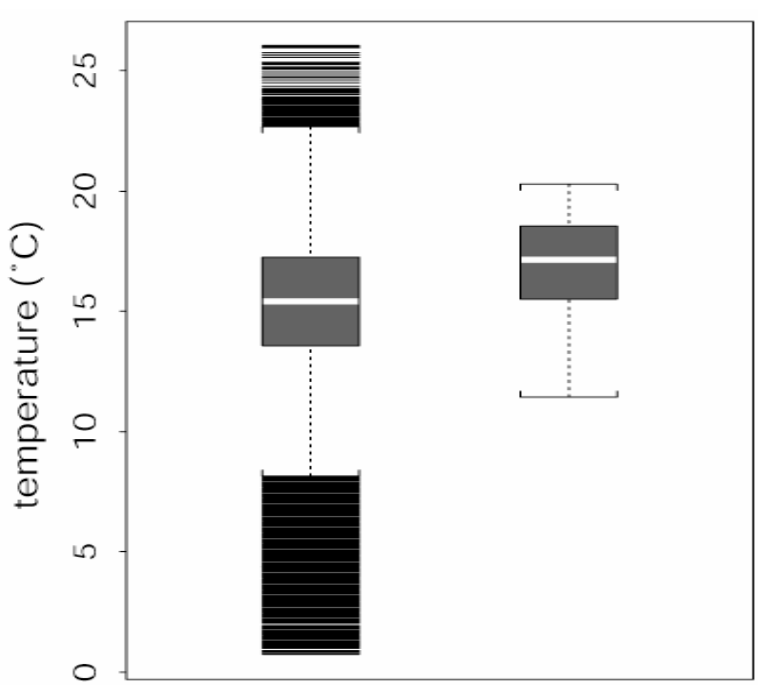

(a)

(b)

Figure 6: Values of the water column stratification index (left) and temperature (right) (i.e., the covariates of the growth model) in the waters located over the shelf and shelf break (a: bottom depth < $1000 \mathrm{~m}$ ) and in oceanic waters (b: bottom depth > $1000 \mathrm{~m}$ )
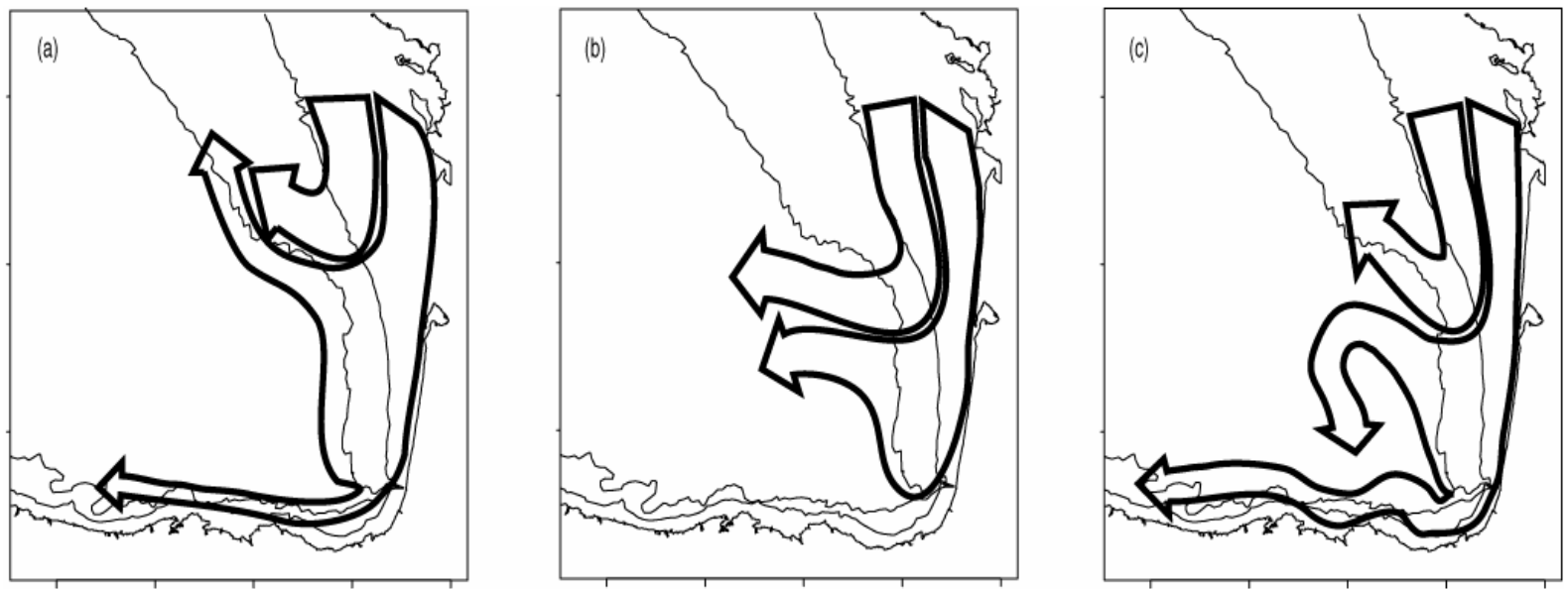

Figure 7: Schematic representation of drift trajectories. (a) U-type configuration dominant in 1997 leading to retention over the French shelf. (b) V-type configuration dominant in 1998 leading to advection west off the shelf. (c) W-type configuration dominant in 1999 leading to retention over the shelf in the north, advection off the shelf in the central part and retention (westward coastal flush) in the south. 
1997

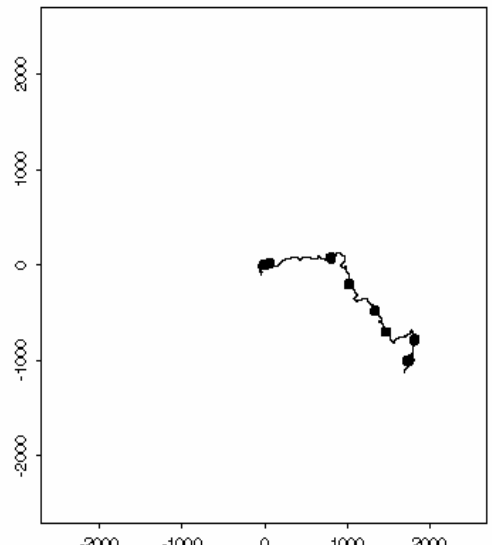

1998

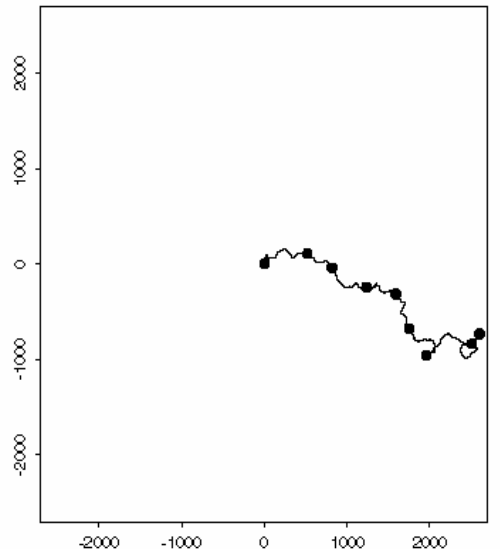

1999

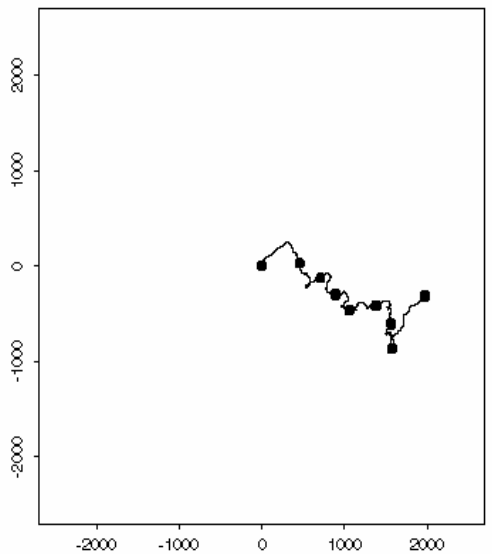

Figure 8: Wind regime (summed wind vector) observed from May to September at Cap Ferret semaphore $\left(45^{\circ} \mathrm{N} ; 1.5^{\circ} \mathrm{W}\right)$ in 1997,1998 and 1999. 

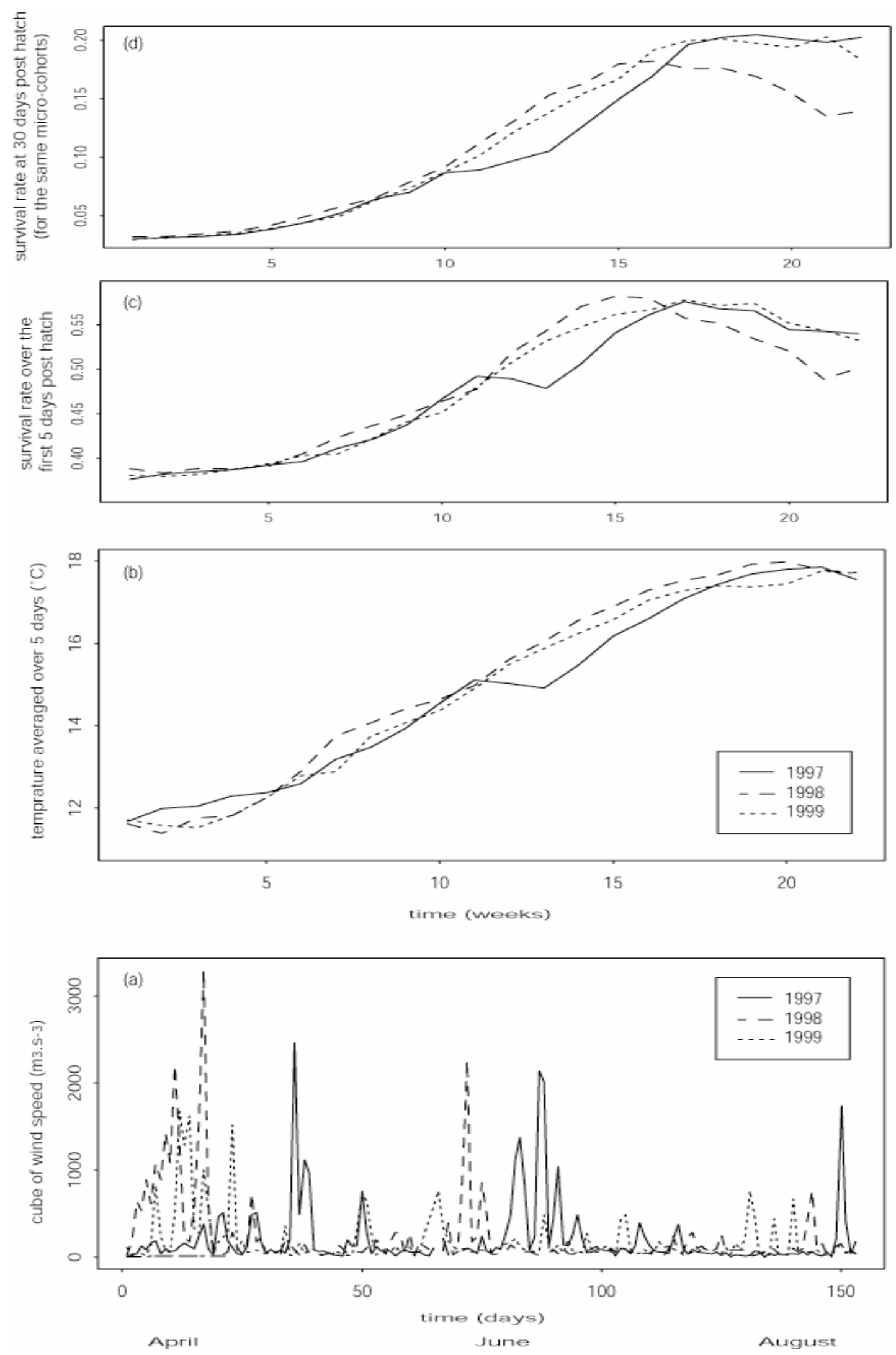

Figure 9: Influence of wind intensity on water temperature $(0-30 \mathrm{~m})$ and larval survival for the years 1997 to 1999. (a) Cube of the daily average wind intensity measured at Cap Ferret semaphore. (b) Average temperature in 0-30 m layer for all the trajectories released on the same week and during their first 5 days of drift. (c) Average survival index for the same trajectories and during their first 5 days of drift. (d) Average survival index for the same trajectories and after 30 days of drift. 
average egg abundance (model based on field surveys)
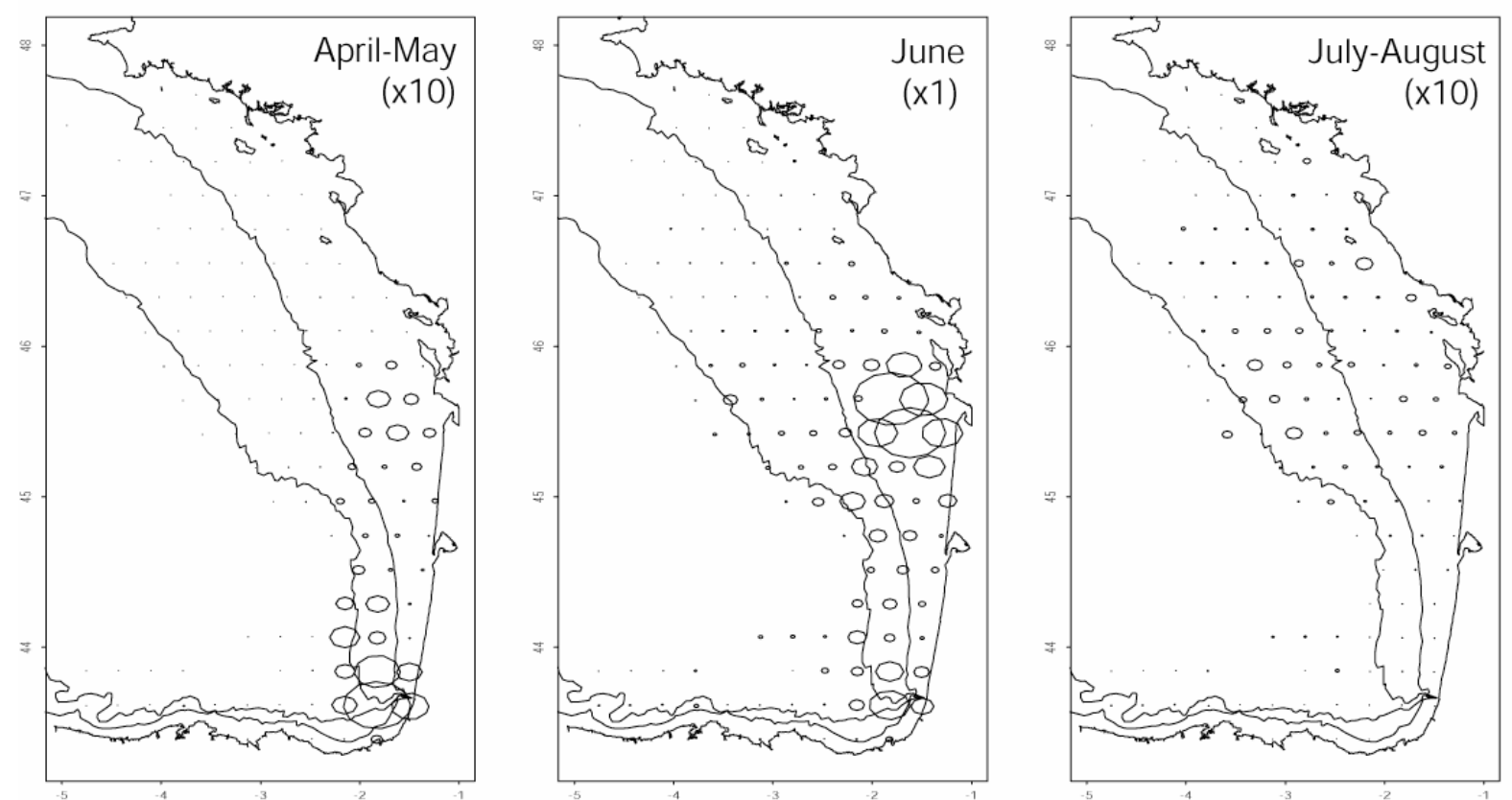

potential survival index (biophysical simulation results)
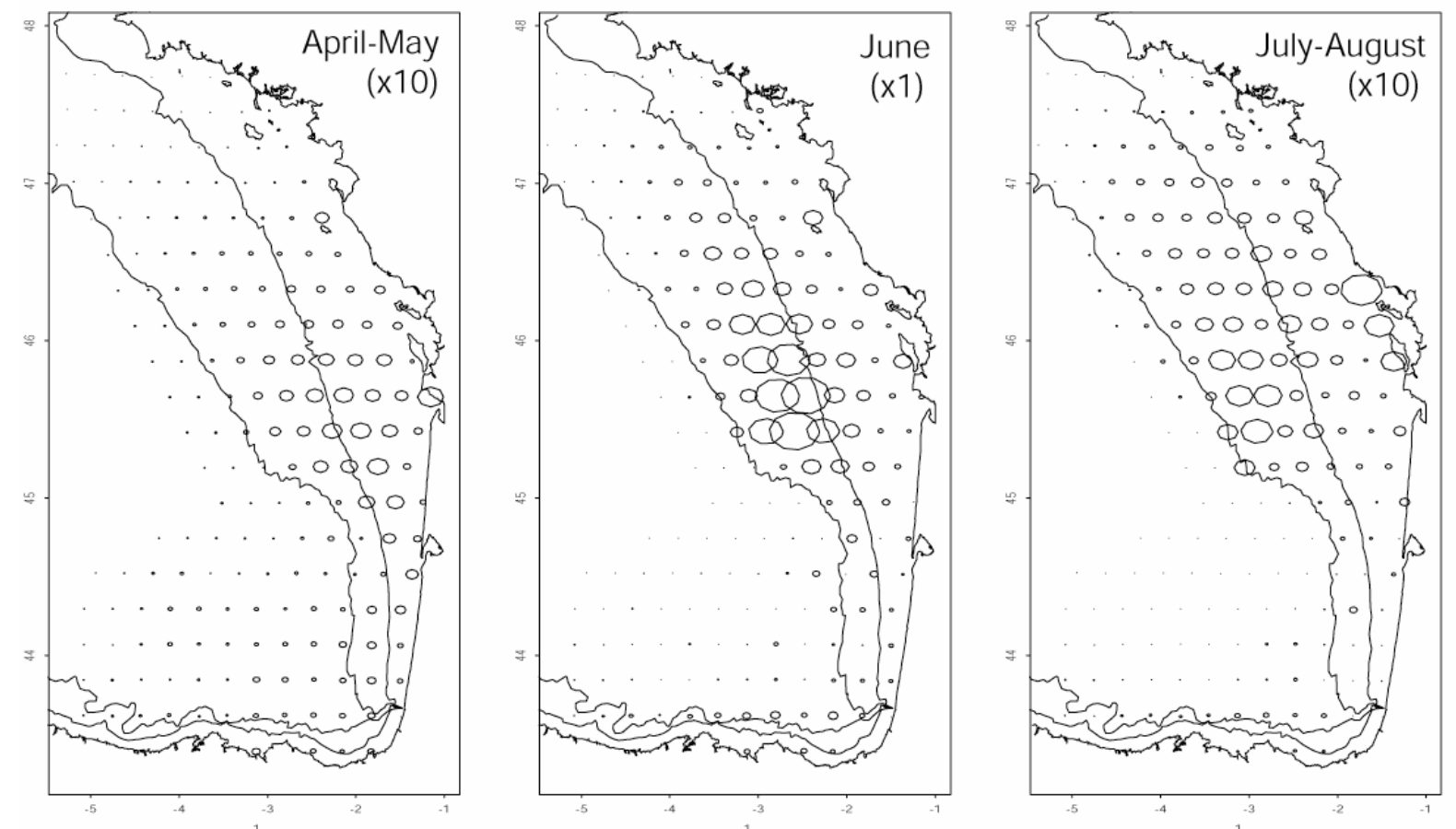

Figure 10: Observed spawning locations (top) and estimated potential annual larval survival (bottom) mapped on the spawning grid for early (April-May), peak (June) and late (July-August) spawning periods. Maps are averages over the years 1997-1999. Larval survival is estimated by summing the survival index for all trajectories originated from each spawning location during the spawning periods. 


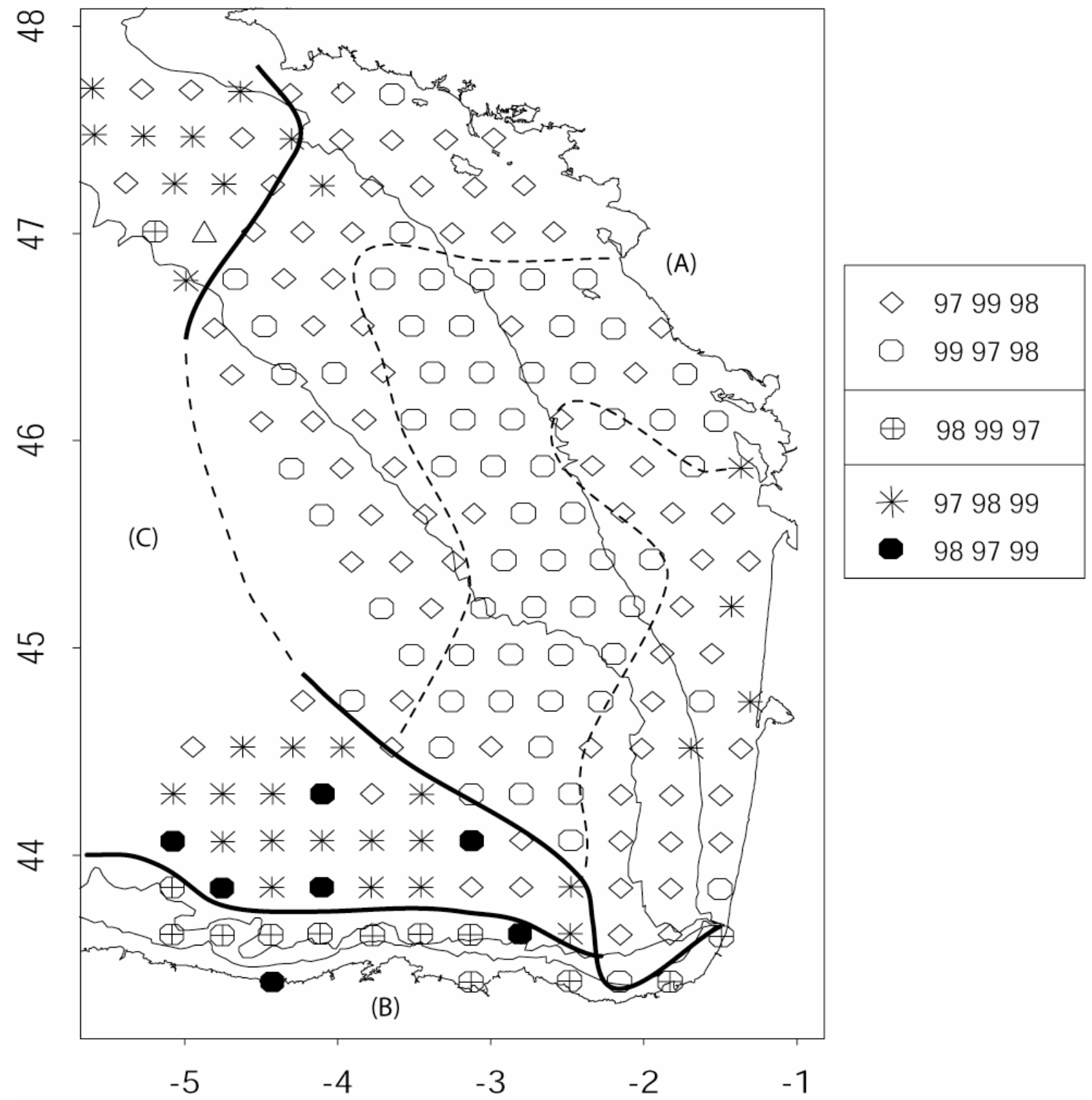

Figure 11: Inter-annual variability in potential larval survival per spawning location according to the biophysical model. For each point of the grid, the symbols represent classes (on the right) defined by ordering the years in descending order of larval survival. 


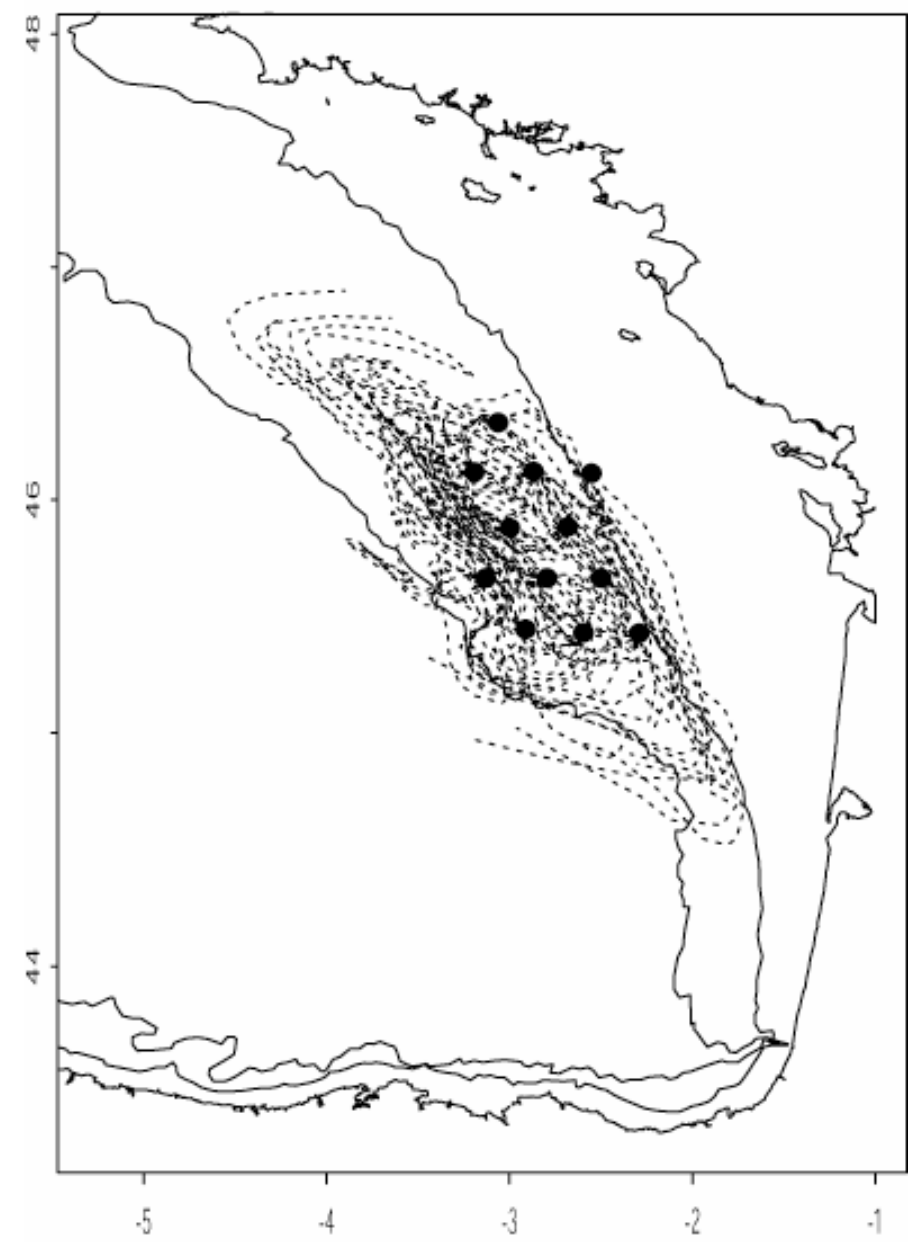

Figure 12 : Drift trajectories (dashed lines) of virtual buoys released weekly from May to July 1999 over the central part of the shelf and tracked for 100 days. Black dots represent release locations. 